\title{
A first experience with a Smart bus for improving public transportation
}

\author{
R. Tostado, A. Rovirosa, J.L. Velázquez, E. Castillo, O. Cervantes
}

Universidad de las Américas Puebla, Computing, Electronics and Mechatronics Department, Ex-Hacienda Santa Catarina Mártir S/N (raul.tostadobz, arturo.bravora, joseluis.velazquez, esteban.castillojz, ofelia.cervantes)@udlap.mx

KEY WORDS: Intelligent Transportation, Smart Bus, Internet of Things, Dynamic Localization, Transportation Routes. Citizens experience design, Open Mobility Data.

\begin{abstract}
:
An alternative to optimize transportation services in the city of Puebla is presented. Main problems tackled to provide advanced transport applications in a Smart City, are described and some available solutions in other countries are analyzed. As a case of study, the challenges for designing and developing a mobile application oriented to users of the buses provided by Universidad de las Américas Puebla (UDLAP) are presented. Users include students, as well as faculty members and administrative employees. The application provides an innovative way of tracking, in real time, movements of the UDLAP transportation buses through the city of Puebla in Mexico. Modeling and technical implementation solved problems are presented and future steps for extending those services to the city of Puebla are also suggested.
\end{abstract}

\section{INTRODUCTION}

Overtime, technology has advanced at a very rapid pace, so it has modernized the population lifestyle as well as the services available in a city ranging from competitiveness to the quality of life of its citizens. Smart cities (Kummitha et al, 2017) as are called this new urban areas, integrate the vision of development through the use of information from every aspect of a city and emerging technologies and trends such as automation, machine learning and the internet of things (IoT) to manage every asset of a city in an intelligent and innovative way (see Figure 1).

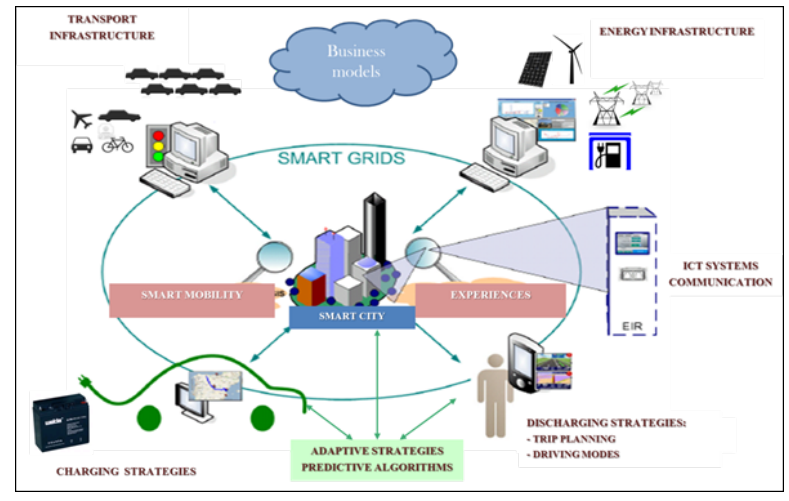

Figure 1. Elements of a Smart City.

Among different aspects of a smart city, mobility and efficient transportation are an everyday problem in an intelligent city (Chun, 2015), considering that there is an increasing number of traffic on the streets and pollution rates. The current use of public transportation as well as the techniques used to optimize this service are not enough for the large number of people who need to go from one place to other every day (Bibri \& Krogstie, 2017).
Crucial for the success of these services is their information quality and their usability. As a consequence, user requirements with regard to these aspects have to be detected, considered and harmonized for achieving the best user experience for passengers (Beul-Leusmann et al, 2013).

The solutions provided must take in account local contexts and be adapted to local user requirements, cultural background and available infrastructure. In fact, the approach for developing smart city services is different in Europe, America and Asia. For instance, European cities like Paris are older than American cities like New York. For example, the wealthy population of America often lives in suburbs away from the city while in Europe wealthier citizens live in metropolitan areas (Chan, 2016).

In general, many cities around the world are providing information services that offer to users precise information about the frequency and position of buses belonging to the public transportation network. But in large cities, the traffic produces unpredictable behavior of bus public transportations services and it is difficult for users to know if they will be able to be on time for catching the next bus or if they need to wait longtime for the next one.

The Smart UDLAP Bus is an experience in Puebla to approach those challenges, providing information that facilitates user's decision-making when using public transportation. The application is oriented to offer a more efficient service for the university users in a small-scale view and could bring great benefits for the state government in a big-scale, offering better services to all citizens combining the information of all public transportation services.

Considering all the above, the remainder of this paper is structured as follows: in Section 2 existing approaches to deal with the mobility and efficient transportation problem are presented. Sections 3, provides details on the design and 
implementation of the Smart UDLAP Bus application. Section 4 describes the usability tests performed to ensure the viability and adequacy to user's needs of the application. Section 5 proposes future steps for the application. Finally, Section 6 presents the conclusions derived from this work.

\section{RELATED WORK}

In this section, the concept of Intelligent Transportation Systems and the related work associated to similar applications techniques to improve mobility in a smart city is presented.

\subsection{Intelligent Transportation Systems (ITS)}

Intelligent transportation systems (ITS) are advanced applications which, without embodying intelligence as such, aim to provide innovative services related to different modes of transport and traffic management and enable various users to be better informed and make safer, more coordinated, and 'smarter' use of transport networks (Nathanail et al, 2016).

Although ITS may refer to all modes of transport, the directive of the European Union 2010/40/EU, made on July 7th, 2010, defined ITS as systems in which information and communication technologies are applied in the field of road transport, including infrastructure, vehicles and users, and in traffic management and mobility management, as well as for interfaces with other modes of transport (European Parliament, 2010).

\subsection{Transportation in Puebla City}

In the last 30 years, Puebla city has gone from being an average city to becoming the central nucleus of the 4th most populous Metropolitan Zone of the country, registering a growing motorization index, having increased by 4.6 times the number of motor vehicles, meanwhile the number of inhabitants doubled (INEGI, 2017).

The need to improve public transportation with more efficient alternatives has been tackled by local authorities starting to offer new services in the last decade. RUTA is an Articulated Public Transportation System, which orders the usual transportation resources and integrates new urban networks. These networks have exclusive (confined) lanes and complementary routes, through which high capacity buses circulate. The RUTA buses have clean technology and connect several points of the Metropolitan Area of Puebla. There are currently two RUTA bus routes, which have some problems in their efficiency since they do not circulate with enough frequency for the users who need it. It is necessary to offer alternatives for improving the quality of service to worldwide standards (RUTA 2017).

\subsection{Similar Smart Mobility Applications}

In this section, we describe some trending applications available in the market, providing services to their communities:

- EMT Madrid: public transport application of Madrid city, Spain, which shows all the bus lines of the city indicating the name of each one, as well as the stops of the same route identified by an ID. The user must use this stop ID to check the expected arrival time to the stop of the next two buses. The application also helps users to calculate the best route from one place to another, considering alternative routes that could help $\mathrm{him} / \mathrm{her}$ to save time. One of the main requirements of this application is that all buses must be equipped with an internet connection, which allows to monitor their position all the time. This application is managed by the Madrid City Municipality (see Figure 2).

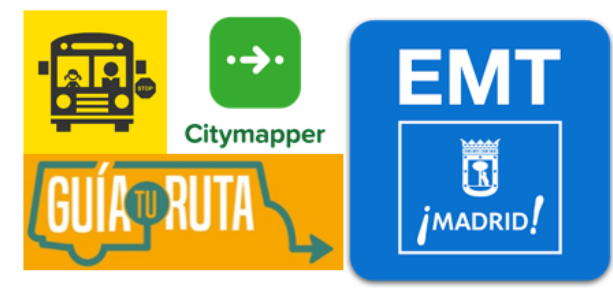

Figure 2. Smart Mobility Application Example.

- Bus Stop: catch your bus on time! application developed by APP Guys Inc. It allows to monitor school buses in the United States, indicating the exact distance to your destination, and allows school communities to chat with each other by instant messages. To be able to monitor your bus, it is necessary first to hire the service (App Guys Inc, 2017).

- Citymapper: indicates the main transport routes in the main capital cities such as New York, Los Angeles, Mexico City, showing the stops as well as the estimated frequency of service for each specific transport type (Citymapper, 2017).

- Guía tu Ruta: Application developed by Benemérita Universidad Autónoma de Puebla (BUAP) students in Puebla, Mexico, designed to help public transport users by pointing out the routes of the different urban routes, as well as helping the administrators to manage their fleet and know where their units are in real time. Informal user tests were performed with this application, but we did not obtain good results, since it is necessary to be previously registered. The current version of the application showed some drawbacks since after the registration of a new user, it indicates that the user already exists and cannot confirm the successful registry (Campos, 2016). 
In general, available applications provide estimated arrival time to stops, but it would be better to know the current position of buses to inform the users with a better estimated arrival time, considering unexpected delays due to traffic or other unplanned urban inconveniences.

\section{SMART UDLAP BUS}

As mentioned in the previous section, there are some applications seeking to improve mobility services in a Smart City (Fernández-Ares et al, 2016). In general, applications show schedules providing static information, indicating all the bus stops on a static map and only some of them provide the position of the buses in real time. In the case of study of the Smart UDLAP Bus, a solution that dynamically calculates the real time position of every bus moving in the network and helps users to know how far is the bus from his/her current position is implemented. Main design decisions as well as technical challenges of the implementation of the mobile application are presented in the following paragraphs.

\subsection{Problem statement}

The UDLAP community transportation service has three main routes whose objective is to help employees and students to reach the university campus from various points of the city (see Figure 3). Each route has a defined schedule indicating the expected time when the bus is supposed to arrive to that stop. But in a growing metropolitan area as Puebla, there are external elements such as traffic that make difficult for the bus to reach stop at that expected time. User does not know how much time is left before the bus arrives to the stop or if the bus has left the stop or if the user must find another means of transportation to reach his destination.

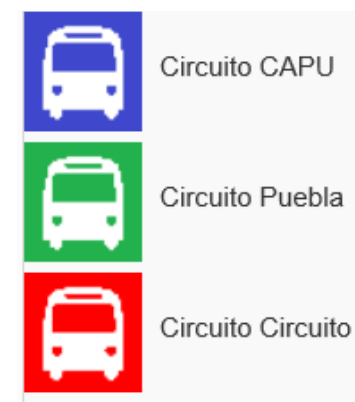

Figure 3. UDLAP Buses Routes.

An experience has been undertaken by a group of UDLAP students to tackle this problem as an example of services that could be available in the city of Puebla. Smart UDLAP is an application for mobile devices (Android and iOS), which seeks to help UDLAP community members to know the exact time of bus arrival to stops. With this application, the user can choose to leave his home earlier or take another means of transportation to be able to arrive to campus on time.

\subsection{Main features}

Considering existing transport applications, Smart UDLAP bus includes the following innovative elements:

- Bus Position: the application indicates at any moment, the position of the bus and this position is updated when the bus moves. This location updating is reflected in the application map with a bus icon that moves across the streets of the city of Puebla. The application offers the advantage of showing bus position updates in near real time, allowing the user to observe the bus path and its exact position at any specific moment.

- Stops of the route. The SMART UDLAP bus application shows on the city map, each of the stops of the three routes of the university transport system by means of an icon. When choosing a stop (click), the application displays an image allusive to stop location, as well as three additional functions:

o take me there: that shows the path to get to the selected destination from the user's current position.

o bus arrival: that calculates the expected arrival time for the next bus, and

o schedule: that shows the complete schedule of the selected bus stop.

- Dynamic route display. The application uses an algorithm that connects each stop with the next stop, tracing the path that the bus travels on the map. This option is useful when the user wants to know the arrival of the bus to a specific stop. This option is implemented by calculating the position of the stop that has already passed the bus, related to the stops that are missing. The algorithm takes the stop the user wants to reach, calculates which stops are between the bus and the destination, and connects each stop to present the route that the bus will travel to the user (see Figure 4).

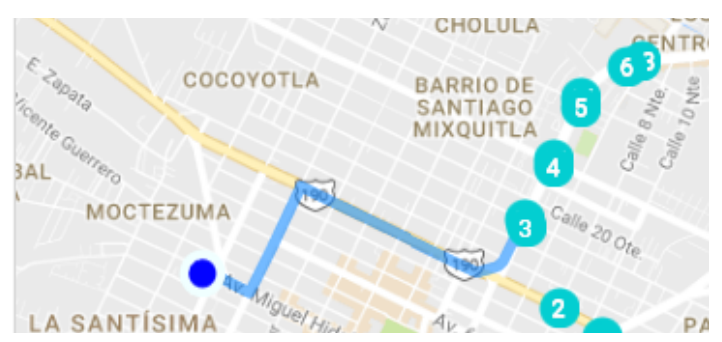

Figure 4. Stops at the map.

- Waiting Time. The application calculates the approximate time the bus will take to arrive at a specific stop according to the current position of the bus. For each intermediate stop, it calculates how long it will take, adds those times and presents them to the user, to obtain an arrival approximate time. 
- Database Update: Every time the bus goes through a stop, the database is updated, so we can know in real time which stops already passed, also thanks to these records we can make future decisions to improve the application.

The Smart UDLAP bus mobile application was developed using Phonegap $^{1}$ (version 3.1.0). The application is available on the Puebla Route for Android. A manager option is under development for extending its services, it will allow to include new routes with its own bus stops and more functions to monitor the performance of each bus on its route.

\subsection{Localization Algorithm}

In order to provide a dynamic and accurate localization service, it was necessary to designed an algorithm that deals with the problem of wrong locations produced by the Global Positioning System $^{2}$ (GPS) sensor when there are multiple bus stops that are near to each other. Figure 5 illustrates this scenario by showing the beginning and the end of one of the university routes, where the margin of error of the GPS sensor does not allow to identify the bus stop correctly. In some cases when the two bus stops are located on each side of the same street, the GPS reports the same position and it is necessary to define the correct location where the bus really.

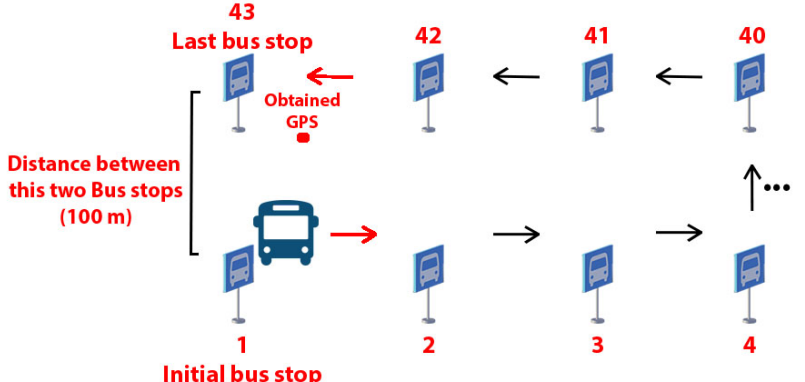

Figure 5. Sensor GPS accuracy error.

An algorithm was designed to solve this problem. It consists of comparing the GPS data of previous bus stops against the current GPS position to determine the correct stop based on previous knowledge. Take again as example Figure 5, where there is uncertainty if the bus is at bus stop no. 1 or bus stop no. 43. Considering that there are stored no previous bus stops, it is more likely that the current position is the first bus stop (instead of the last one).

In the case of Figure 6, where it is necessary to define if the bus is at stop no. 2 or bus stop no. 42 , there is a previous knowledge

\footnotetext{
${ }^{1}$ Phonegap: https://phonegap.com/

${ }^{2} \mathrm{~A}$ space-based radio-navigation system that provides the localization of an object.
}

(past correct/incorrect bus stops as well as the current GPS data) that is used to determine that the current stop is the second one. Creating the registry of the bus locations allows to determine the nearest and correct bus stop when there are multiple intersections. This algorithm allowed to improve the university bus tracking.

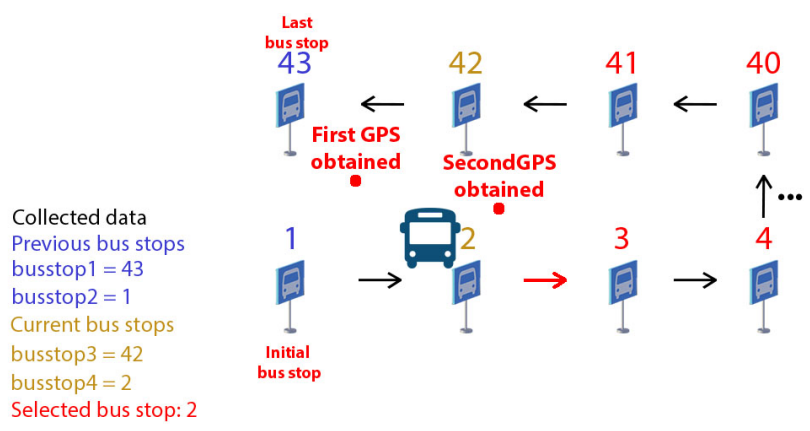

Figure 6. GPS Sensor Error Correction Algorithm.

It is important to notice that in the case of bus stops that do not intersect, the collected GPS data are used without any additional checking, because the GPS sensor radius is around six meters accurate.

The algorithm uses a database that contains the exact position of each bus stop and also registers all the locations reported by the bus on its route. It is planned to use the data reported by the buses on their routes for future analysis to provide a better understanding of the impact of the traffic on their planned paths.

\section{USABILITY TEST}

After the development of the application, it was necessary to perform some tests to ensure its correct operation, as well as to know the opinion of the users to evaluate its utility and ease of use for navigating within the application. The following sections show obtained results.

\subsection{Pilot test}

The goal to perform the pilot test was to evaluate how correct and effective was the application considering its fonctionalities and the user experience perspective. The first step consisted on establishing expected results and to verify that all the functionalities were working correctly. For accomplishing those tasks, the group was divided into two working teams: one team for monitoring the bus from the University (as a master control) and a second team aboard the bus to verify the GPS accuracy. From the three university routes, the Puebla route was selected to verify each one of the stops of the bus taking evidences to include in the application (see Figure 7). 


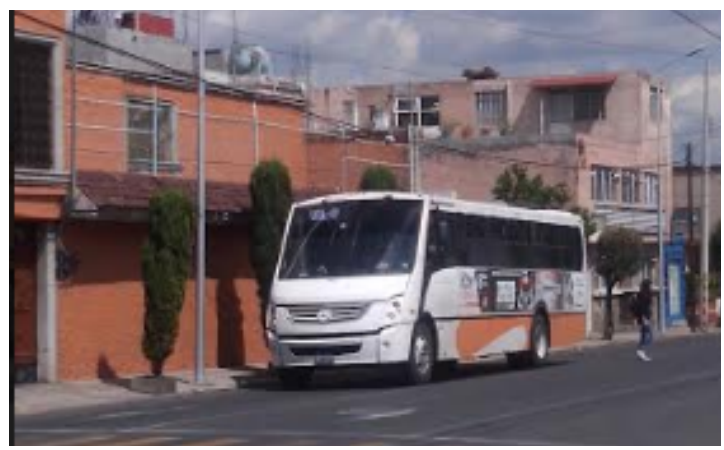

Figure 7. UDLAP Bus at one Stop.

The pilot test was very helpful to detect that there were some minor mistakes numbering the stops and showed the need to improve the localization algorithm. New ideas also emerged for making the application management more flexible and easy to understand by users. Some adjustments were made to the original code, for instance, improving the visualization of the bus direction (see Figure 8)

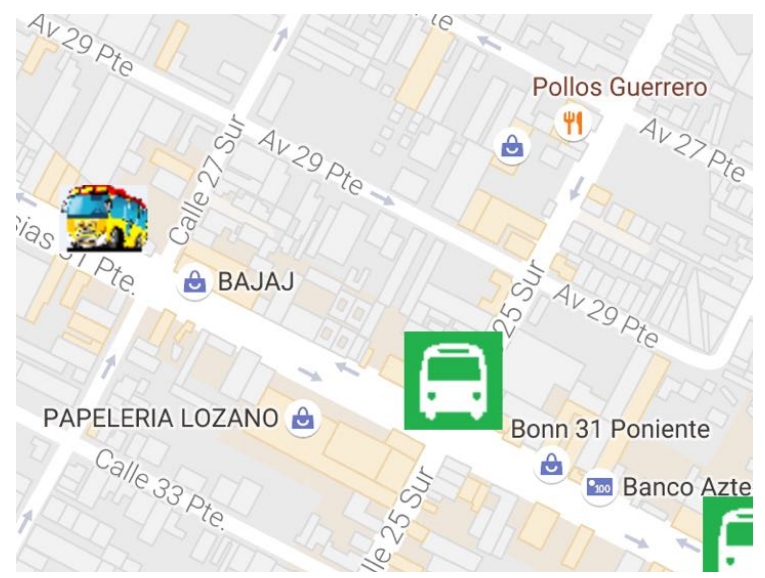

Figure 8. UDLAP Bus First Version.

\subsection{Making the poll}

In order to evaluate the most important characteristics of the application from the user's perspective, some tasks and questions, were prepared to obtain feedback from twenty potential final users from the university community that were randomly invited to participate. The questions focused on usability, performance, user friendliness, etc.

\subsection{Test application}

The evaluation of the Smart UDLAP bus application was accomplished with two working teams and twenty selected users that accepted to participate in the test. The usability test took place on the Puebla Route, early in the morning of a Friday (regular working day).
The mobile application was installed on three different devices that were available to offer to the public. The stops were monitored all the way until the first passengers boarded the bus. While users were boarding, they were invited to participate in the evaluation test and received general information about the mobile app working on different Android devices in order to be able to test the functions of the mobile app during the trip and answer the poll lately for evaluating the key features.

The following results were obtained:

- Users satisfaction: Figure 9a shows that $70 \%$ of students scored 5 and $30 \%$ of 4 on a 5 -point scale. It means that in general terms, users liked the application.
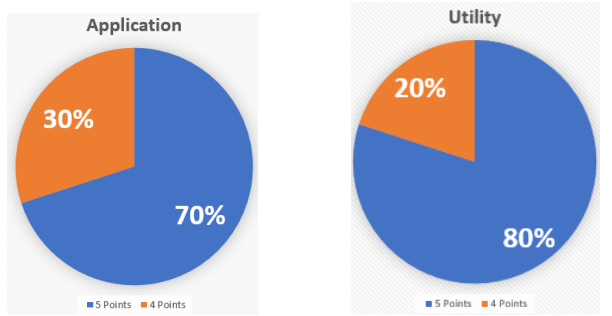

Figure 9. a) user satisfaction and b) application utility

- Application utility: Figure 9b, illustrates that $80 \%$ of the students scored the application with 5 and the remaining $20 \%$ of 4 . It means that students considered that it would be very useful for them to use this application every day.

From the comments expressed openly by some of the users, as final questions in the evaluation form, some suggestions were collected oriented to improve the user experience, such as: changing some colours, or the size of some icons, etc.

\section{FUTURE STEPS}

In order to be able to extend the services provided by the Smart UDLAP Bus to the Puebla City, specifically in the lines of the RUTA transport system, the following steps are needed:

- Consider the UX design recommendations proposed by the users in the usability testing, for increasing the application friendliness.

- Explore more alternatives for tracing the movement of buses to obtain more precision than the one provided by the GPS actually used.

- Extend the services provided by the Smart UDLAP bus application to include new modules oriented to the manager in charge of updating (adding and deleting) the bus network describing available routes.

- Develop new data mining services that will provide insight on bus performance collected data and will help to improve the quality of service of the RUTA transport system. 
The implementation of the Smart Bus in the RUTA system would produce the following advantages:

- Saving time: Citizens would be able to know the exact moment at which the bus will pass, so they could calculate the time before leaving home.

- Predicting arrival time: It would be possible to estimate the time at which citizens would arrive at a certain place.

With the automation of the RUTA system, it would also be possible to develop new functionalities such as: counting the number of users and planning the adequate number of buses to provide a better service to Puebla citizens.

\section{CONCLUSIONS}

Developing this first version of the application shows that the technology is available for providing better services to Puebla. The application is user-centered design. It is intended to be friendly and easy to use by any kind of citizen. It is a key feature, for encouraging the users to spread a positive opinion of the application and for convincing more people to use it.

By the other hand, it is very important nowadays to use green technologies, following the trends to promote more awareness to take care of the environment. The technologies used by the Smart UDLAP bus could contribute to improve the management of the transportation system of Puebla, providing information for controlling circulating buses and then contributing to decrease $\mathrm{CO} 2$ emissions in the city.

\section{ACKNOWLEDGEMENTS}

We acknowledge and thank the support of Rogelio Velázquez, Raúl González and José Emmanuel de los Santos, students in the UDLAP Honors Program that participated in the pilot and usability tests. We thank also the UDLAP Transportation Services for their support for accomplishing the technical and usability tests. This work has been partially supported by the Red iCluster Puebla project, belonging to the iCluster initiative (Ecosystem for Innovation and Entrepreneurship) financed by the Mexican Ministry of Economy.

\section{REFERENCES}

App Guys Inc, 2017. Catch your bus on time, Alberta, Canada https://itunes.apple.com/us/app/bus-stop-catch-your-bus-ontime/id1177176897? $\mathrm{mt}=8$

Beul-Leusmann S., et al., 2013. User-centered design of passenger information systems. Conference: Professional Communication Conference) IPCC), IEEE International. DOI:10.1109/IPCC.2013.6623931

Bibri, S., Krogstie., J., 2017. Smart sustainable cities of the future: An extensive interdisciplinary literature review. Elsevier Sustainable Cities and Society, Vol 31, pp. $183-212$.
Campos T., 2016. Guía tu ruta: una app diseñada en Puebla para facilitar el transporte público, Mexico City, Mexico https://www.xataka.com.mx/aplicaciones-parasmartphones/guia-tu-ruta-una-app-disenada-en-puebla-parafacilitar-el-transporte-publico

Casey Chan, 2016. Why Are American Cities So Much Different Than European Cities?, New York, USA http://sploid.gizmodo.com/why-are-american-cities-so-muchdifferent-than-european-1788196723

Chun B.T., 2015. A Study on Intelligent Traffic System related with Smart City. International Journal of Smart Home, Vol 9, pp. $223-230$.

Citymapper Limited 2017. Citymmaper Application Information, Mexico City, Mexico citymapper.com/df.

European Parliament, 2010. Directive 2010/40 Official Journal of the European Union, European Union eur-lex.europa.eu.

Empresa Municipal de Transportes de Madrid, 2015. EMT Madrid Application, Madrid España emtmadrid.es.

Fernández-Ares, A., Mora, A.M., Arenas, M.G., GarcíaSanchez, .P., Romero, G., Rivas, V., Castillo, P.A., Merelo J.J. 2016. Studying real traffic and mobility scenarios for a Smart City using a new monitoring and tracking system. Elsevier Future Generation Computer Systems, Vol 1.

INEGI, 2017. Mexico in Figures. Consulted on June 10,2017. http://en.www.inegi.org.mx/app/areasgeograficas/?ag=21\#

Kummitha, R., and Crutzen, N., 2017. How do we understand smart cities? An evolutionary perspective, Elsevier Cities, Vol 67, pp. $43-52$.

Nathanail, E., Gogas, M., Adamos, G. 2016. Smart Interconnections of Interurban and Urban Freight Transport towards Achieving Sustainable City Logistics. Elsevier Transportation Research Procedia, Vol 14, pp. 983 - 992.

RUTA, 2017. Características de RUTA, Puebla, México http://rutapuebla.mx/caracteristicas-de-ruta-puebla/ 